\title{
TOWARDS HOUSING POLICIES THAT CONSIDER HOUSEHOLD'S PREFERENCES: ESTIMATING THE DEMAND FOR HOUSING ATTRIBUTES IN CHILE
}

\author{
Esteban LOPEZ1, ${ }^{*}$, Dusan PAREDES ${ }^{2}$ \\ ${ }^{1}$ Department of Urban and Regional Planning, University of Illinois, Urbana 61801, USA \\ 2 Department of Economics, Universidad Catolica del Norte, Avenida Angamos 0610, Antofagasta, Chile
}

Received 17 March 2016; accepted 8 June 2017

\begin{abstract}
Understanding household preferences for housing attributes is imperative for developing countries after years of housing policies that failed mostly due to the mismatch between housing solutions and needs. This paper provides income and price elasticity estimates of the demand for housing attributes as an indicator to measure how households perceive housing attributes (necessities or luxuries). These metrics are important because they allow evaluating previously national-level housing policies as well as suggesting new paths of action that are in accordance to households' preferences. The study focuses on Chile because its influential role in designing housing policies in other developing countries (Gilbert, 2002). Using five cross-section household surveys from 2000-2011, our results suggest that Size and Location are perceived as basic necessities. Contrarily, Quality and Housing Features are considered luxury goods. Size and Location are more price-inelastic than other attributes. These results are consistent across regions, and suggest that households prefer larger and better-located houses.
\end{abstract}

Keywords: almost ideal demand system, housing attributes, Chile, housing demand, housing policy.

Supplementary material associated with this article can be found, in the online version, at https://doi.org/10.3846/ijspm.2018.320

\section{Introduction}

In Latin America Chile has established a reputation as a country with a consistent reduction in the housing deficit over the last twenty-years. However, this reputation has lately been disputed by the alarming lack of quality in the provision of public housing (Chamorro, 2013), which has opened the debate to the need of rethink the way public housing is provided. As many developing countries, in Chile primarily used direct aid (i.e. construction and purchase subsidies) as the principle channel that encouraged ownership as a way to solve housing needs. However, the deficient quality standards of direct-aid housing programs have raised concerns regarding not only about how to improve quality, but also about the need to understand which are those housing attributes that consumers value the most and how they might interact to improve the consumer welfare of housing policy beneficiaries (Follain \& Jimenez, 1985). The fact that in Latin America the housing subsidy has increased (Gilbert, 2011) and few direct-aid housing programs have succeeded (Gilbert, 2014) strongly suggest that these programs were designed without consideration what the intended beneficiaries want in terms of housing attributes.
This paper aims to alleviate the lack of information about the economic valuation of housing attributes by estimating a demand model that allows the calculation of price and income elasticities of housing attributes. These estimations are crucial inputs when it comes to designing future housing programs (Greene \& Ortúzar, 2002). For example, price elasticities reveal how sensitive households are in their demand to changes in the price of housing attributes and hence whether they are perceived as either substitutes or complementary goods. This helps us to understand the level at which each attribute's demand will contract or expand to changes in their own price as well to fluctuations in other goods. Specifically, price elasticities might reveal that the quantity demanded of housing location is highly sensitive in itself (i.e. significant changes in demand in response to small variations in the price of housing location), as well as the degree to which households will be willing to trade the consumption of other housing attributes to maintain their consumption of housing location. Second, income elasticities provide a measure of the sensitivity of consumers' demand to income

*Corresponding author. E-mail: esteban.lopez@uai.cl 
changes, which allows the classification of housing attributes as needs or luxuries. This is a key measure in a country where the reduction of income inequality is a priority on the political agenda since those attributes (revealed as necessities) should be prioritized when designing subsidies as opposed to those revealed as luxuries. These two measures offer a clear picture of how consumers demand housing attributes, providing useful insights to align policy accordingly.

Additionally, we argue that Chile's particular geographic conditions require the use of a regional approach in the estimation of demand. Considering that Chile covers $4,270 \mathrm{~km}(2653 \mathrm{mi})$ from north to south, it is expected that Chile's regional divisions also represent different geographic, climatic, and economic contexts each of those with a particular housing market. Chile has desert in the north, is mediterranean-like in the center and has rainforest and sub-polar forest in the mid-south and extreme southern regions. We suspect that these climatic and geographic differences are translated into consumer preferences for housing attributes that are spatially heterogeneous. For example, southern regions require a higher quality of walls and roofs in order to face hard winters, while northern regions' absolute lack of rain hardly requires anything similar. To test our hypothesis about the potential spatial heterogeneity, we include in the demand system socio-demographic and local amenity components that allow us to differentiate the elasticity by both consumer characteristics and local-regional preferences.

We estimate a two-step procedure using cross-section household data from 2000, 2003, 2006, 2009 and 2011 in order to identify the demand system for housing attributes in Chile. Following Garcia and Raya (2011), we group housing characteristics in four broad dimensions: Housing Size (number of bathrooms, bedrooms, size), Housing Quality (floor, wall and roof quality), Housing Features (water heater, washer, refrigerator, landline and computer) and Housing Location (approximated from other available variables). In the first step, we estimate a hedonic function using a log-linear model in which empirical issues such as the inclusion of household characteristics and the demand for housing features are addressed. The second step estimates an Almost Ideal Demand System for Housing Attributes (AIDS-HA hereafter) in order to calculate income and price elasticities. We incorporate a third stage in order to estimate confidence intervals for the calculated elasticities using bootstrapping so that we might evaluate regional differences.

Our results can be summarized in three main findings. First, Housing Size and Housing Location are considered normal goods or basic necessities as opposed to Housing Quality and Housing Features, which are classified as luxuries. Second, own-price elasticities suggest that Housing Size and Housing Location are more inelastic than Housing Quality and Housing Features. This implies that the consumption of these two goods would not decrease as much as it would for the other goods if prices change. Third, our estimations provide partially significant evi- dence to support spatial heterogeneity in the demand for housing, only partly accepting our hypothesis regarding their existence. In this paper we argue that these results are important evidence that should be considered by policy makers when evaluating current housing programs and when designing future public housing options.

The section that follows reviews how the context of Chile's current housing policy has evolved accordingly to the economic development of the country into one that focuses on the need for more profound and detailed information regarding consumer preferences. We argue that this results from the need to formulate housing policy that is in accordance with Chile's current economic growth levels as well as its OECD peers. We then discuss the theoretical approaches for the estimation of a demand system for housing attributes, pointing out the contribution of this paper to the current literature. Sections 3 and 4 present the economic model and the empirical methodology, respectively. Subsequently, the data is presented and the remaining sections explain the results followed by the main conclusions.

\section{Housing policy in Chile}

As in most Latin American countries, Chile's housing policy has transitioned through different mechanisms designed regarding the country's different stages of economic development. According to Chamorro (2013) Chile has passed through three clearly differentiated phases of housing policy. The first phase began in 1905 and it was created with the intention of reducing sanitary and health problems associated with the illegal construction of housing in the peripheries of large cities. The project was entirely government funded and, the state created the Housing Council (Consejo Habitacional in Spanish), in order to provide housing services to the poorest population of the country. The main features of this policy were: 1) it was integrally provided and funded by the government and the consumer did not play any role in financing it, and 2) the policy inevitably pursued a high number of housing projects but with very low costs and quality standards due to the high expenditure pledged by the government. Neither characteristic took into consideration how housing characteristics are valued by consumers or the type that would improve their welfare level. Moreover, the existence of economics of scale implied that characterizing the demand for housing attributes was not a relevant factor for most of these projects since they were built using similar architectural designs and were erected in cities' peripheral areas with precarious access to amenities and transportation systems.

By 1965 , the policy was highly criticized due to its poor performance in achieving its proposed goals. According to MINVU (2004) between 1906 and 1925 the government built around 400 houses. The policy was hardly sustainable in the long run due to the excessive government expenditure. This resulted in a housing policy with a low quality of services as well as significant hurdles in introducing new projects. 
The second phase of housing policy took place between 1965 and 2010 during which it was modified towards a subsidiary system that contemplated households that would partially contribute to financing the projects. The government developed a new institution called Housing Corporation (Corporación Habitacional), which was managed by the first Housing Ministry. The role of this entity was to design the best way for assigning housing projects to lowincome households. This effort was the first to generate an improvement in housing quality, which required a system of revealed preferences in order to calculate consumers' monetary contribution towards financing their housing. However, there is no record of these estimations.

Although this complementary approach between the government and households generated clear improvements in the structural characteristics of housing, it still had serious weaknesses. The policy was the first demand subsidy in Latin America (Rubio, 2006): the savings generated by households as their contribution were added to the public subsidies, which the private sector received in order to construct the homes. The main problem with the new system was that the state provided full subsidies for the lowest income groups instead of incorporating a shared investing system. These groups revealed their economic situation through surveys generated by the government such as the Social Protection Survey (Ficha de Protección Social in Spanish), which contemplated fixed thresholds to determine access to housing subsidies. As a result, an initial problem of the policy was the creation of incentives for higher income households to be misclassified as poorer ones and hence to be included in the housing programs which resulted in significant over financing by the government. Another problem was the abandonment of low-medium income families, as their income levels where either too high to be able to apply for a full subsidy, or too low to generate savings in order to apply to the dual financing plan. This group grew over time as well, highlighting a serious drawback to the system.

This entire scenario resulted in low quality housing, a lack of competition in the housing market with serious losses in the bargaining power of households (Richards, 1995). Note also that the assignment of housing still lacks a sorting of the consumer preferences regarding housing attributes. In other words, households must choose a project with attributes defined by government standards and consequently, cannot select houses according to their preferences. Furthermore, and because of the government restriction to selling or renting subsidized housing, households had no access to the complete pool of existing houses in the market, which limited their access to labor markets (Soto \& Torche, 2004).

The third and final phase of housing policy started in 2010 when the Chilean government passed its most recent housing reform. According to Chamorro (2013) this last effort aims to increase self-selection. In other words, households now have an incentive to reveal their real purchasing power in order to improve the matching between demand and supply. Note that this program is strongly focused on revealing households' preferences. There is, however, a problem. Empirical evidence regarding the attributes households are interested in and the economic relationships between them does not exist. According to Caldera Sánchez (2012) the current housing policy is a crucial factor in understanding the inequality and poverty of Chile. The current subsidy system is designed solely for ownership and thus it does not allow access to rented houses in which households' preferences might be incorporated in the search process. As it is points out in Caldera Sánchez (2012); "taxing housing so owing is not favored over renting would reduce distortions and make the tax system less regressive [...]", "enhancing the responsiveness of housing supply to demand would ensure there is a good match between housing construction and demand, and avoid that public support gets capitalized into housing prices" (p. 2).

\section{Literature review}

The literature regarding the estimation of housing demand and its elasticities is clearly marked by a first wave of papers that use several specifications of demand systems based mostly on restrictive parametric assumptions. Pioneer articles in this first wave include King (1976) and Mcmillan (1979) who propose a two-step procedure for the evaluation of housing as a bundle with distinct and recognizable attributes while providing evidence of different price and income elasticities. In this two-step approach, implicit prices for each attribute are estimated in a first round, and then used for the estimation of housing demand and other indicators in the second one.

Even though King (1976) and Mcmillan (1979) recognize that the results of these two-step approaches are strongly constrained by the quality of their data, the estimation of elasticities allows them to suggest that structural housing characteristics are both inferior and complementary commodities, as well as the existence of higher substitutability among housing attributes when comparing housing with other goods. Additionally, both articles highlight the relevance of the estimation of elasticities through demand systems. In this regard, Mcmillan (1979) states that "what has been successfully demonstrated, however, is that a household's preferences for public type commodities can be revealed through systems of equations models" (p. 187). In other words, the authors established the basis for the empirical estimation of housing demand systems.

In the line of two-step approaches, Awan, OdlingSmee, and Whitehead (1982) analyze how household characteristics and the location of household activities affect the demand for housing attributes. Using data for London, they point out space as the housing component with the highest relevance (i.e. a necessity), as opposed to Housing Quality, which shows a high-income elasticity, specifically higher than one, and thus will be considered a luxury. Regrettably, the authors recognize that low quality 
data makes it impossible to perform additional analysis due to the lack of significance in the estimated coefficients as well as the restrictions imposed by the Linear Expenditure Demand System that was used. Lim, Follain, and Renaud (1984) and Follain and Jimenez (1985) proposed similar theoretical frameworks but with a special emphasis on willingness to pay (WTP) estimates. These articles found that a household WTP for space is less than the cost of providing it, which has evident policy implications. Regardless of the empirical focus, this first wave in the literature established the use of demand systems as the theoretical framework for the elasticity estimates.

A second wave of articles has contributed to the discussion through the incorporation of flexible functional forms that fulfill the theoretical constraints in the consumer maximization problem. The Almost Ideal Demand System (AIDS) (Deaton \& Muellbauer, 1980) has been very influential in the study of the demand for housing attributes. The turning point can be tracked to Parsons (1986) who approached the estimation of housing demand by applying the AIDS to the context of respective attributes yielding the Almost Ideal Demand System for Housing Attributes (AIDS-HA). AIDS-HA is a flexible demand system with a closed functional form and welldefined microeconomic properties where homogeneity, symmetry and adding-up are maintained in the hypothesis. In his application of seven US cities, Parsons found that the highest income elasticity (i.e. a luxury good) was for Housing Features, while the lowest was for Housing Quality (i.e. a necessity good). Regarding price effects, the highest elasticity was also for Housing Features and the lowest for Neighborhood Quality. Besides the clear and interesting application, the incorporation of the AIDS approach undoubtedly brought microeconomic consistency to this literature, giving us a rational framework for our analysis. Although with less microeconomic consistency in calculating elasticities, interesting empirical exercises in this line are Arimah (1992) and Pasha and Butt (1996).

Following this line, Cheshire and Sheppard (1998) highlighted the importance of having functional forms theoretically grounded on a utility function. This work also incorporated theoretical constraints derived from the maximization utility problem. The authors estimate a linear version of the AIDS and find that income elasticities for the British housing market are somewhat larger than previous estimates for North American cities. Interestingly, they also evaluate their estimations along income levels and find significant differences between high and low income households.

Garcia and Raya (2011) is the most similar article to our own proposed research considering both the subject and contemporaneity. The authors use an AIDS-HA to carry out elasticity estimations for Barcelona, Spain. Following King (1976) and Parsons (1986), they cluster housing characteristics into three groups: Quantity, Quality and Location. Their results indicate that housing Location is very price-inelastic, suggesting that a consumer will sacrifice Quality and Quantity in order to maintain Location when prices increase.

This paper contributes to this body literature in three areas. First, we establish a demand system for the representation of the spatial heterogeneity of preferences between housing markets within a country's regional markets. While previous literature only performed estimation exercises at country or city level, our work is different in that we argue that considering a single market is unsustainable in light of Chile's economic geography. This issue was also pointed out by Paredes and Iturra Rivera (2013), who estimate regional housing price indices for Chile using an AIDS. Even when the authors do not report elasticities, they show how economic geography can affect the stability of the demand system parameters.

Second, most of the literature reports comparisons between elasticities without adding the corresponding statistical tests to evaluate whether these parameters are statistically different among housing attributes or spatial units. We overcome this point by offering confidence intervals for the estimated elasticities by bootstrapping.

Third, in the context of the current body of literature, this is the first estimation of both the demand for housing attributes and the income and price elasticities for Chile. Although willingness to pay estimates have been provided for the case of Chile (Greene \& Ortúzar, 2002), this paper falls outside the scope of this work due to their use of a discrete choice approach, their limited geographic focus (Metropolitan Region of Santiago only), as well as the absence of elasticity estimations. Besides the usefulness of our proposed estimates for the country itself, evaluating Chile's housing demand and its potential strengths and weaknesses is also important for other developing countries that have been using Chile as an example in setting their own housing policy (Gilbert, 2002). Regarding housing policy in Chile and its potential impact on other developing countries, we hope that our paper encourages the inclusion of spatial considerations and confidence intervals previously ignored in matters of housing policy.

\section{Economic model}

As we specified in the previous sections, we use an economic model consisting of two steps. In the first, we obtain prices for each one of the housing attributes defining the housing bundle, for which we only have renting prices. Our model choice is based on the model of hedonic prices suggested by Rosen (1974). In a second stage, we present the AIDS-HA as a flexible demand system that uses the hedonic prices obtained in the first stage for estimating income and price elasticities of housing attributes. Since both models have been widely discussed in the literature, we prefer to discuss only the core elements for each one here ${ }^{1}$.

The household is a representative economic agent that consumes a heterogeneous good called housing that is

\footnotetext{
1 See Parsons (1986) for additional details.
} 
composed of attributes $Z\left(z_{1}, z_{2}, \ldots z_{n}\right)$. Simultaneously, households also consume a composite good $X$ and preferences for both goods are represented by a well-behaved utility function $U(Z, X)$. This utility function is assumed to be weakly separable between housing attributes and the composite good. Households are price takers and they face a non-linear budget constraint $Y=P(Z)+X$ where the housing price is a function of attributes $Z$, while the price for $X$ is normalized to the unity. Supply of housing attributes affects the hedonic price function, but it is assumed as an exogenous factor.

The utility maximization subject to the constraint generates a demand function for each one of the $n$ housing attributes:

$$
z_{i}=f\left(p_{z 1}, p_{z 2}, \ldots, p_{z n} ; Y\right)
$$

where: $p_{z}$ is the partial derivative of the hedonic price with respect to each one of the $n$ elements of $Z$. The demand functions for each $z_{i}$ must fill the theoretical constraints required by the neoclassical framework of utility maximization. To carry out these conditions, we specify an AIDS-HA. Assume a PIGLOG functional form for the expenditure function that can be expressed in the budget share form as follows:

$$
\begin{aligned}
& \log e\left(p_{z 1}, \ldots, p_{z k}, \bar{u}\right)=\alpha_{0}+\sum_{k} \alpha_{k} \log p_{z k}+ \\
& \frac{1}{2} \sum_{k} \sum_{j} \gamma_{k j}^{*} \log p_{k} \log p_{j}+\bar{u} \beta_{0} \prod_{k} p_{z k}^{\beta_{k}},
\end{aligned}
$$

where: subscripts $j$ and $k$ are the $j^{\text {th }}$ and $k^{\text {th }}$ attributes; $\alpha, \beta, \gamma$ are parameters that define preferences and $p_{z}$ are the recovered hedonic prices. Using the Shepard Lemma, the expenditure function is differentiated to get the demand function $z_{i}$, but in the budget-share form:

$$
\begin{aligned}
& w_{i}=\alpha_{i}+\sum_{j} \gamma_{i j} \log p_{j}+\beta_{i} \log \left(\frac{x}{H}\right) \\
& H=\alpha_{0}+\sum_{k} \alpha_{k} \log p_{k}+(1 / 2) \sum_{k} \sum_{j} \gamma_{k j} \log p_{k} \log p_{j} ; \\
& \gamma_{i j}=(1 / 2)\left(\gamma_{i j}^{*}+\gamma_{j i}^{*}\right),
\end{aligned}
$$

where: $w_{i}$ is the share of the total expenditure assigned to the housing attribute $i$, namely $w_{i}=p_{z i} z_{i} / x$, and $x=\sum_{i} p_{z i} z_{i}$ is the total expenditure on housing attributes. Additionally, the demand system satisfies the necessary conditions such as adding up, homogeneity and Slutsky symmetry. Following Ray (1983) and Parsons (1986), we decide to include a demographic component to incorporate the heterogeneity of preferences of housing along with the distribution of households' characteristics:

$$
w_{i}=\alpha_{i}+\sum_{j} \gamma_{i j} \log p_{j}+\left(\beta_{i}+\theta_{i}^{\prime} d_{i}\right) \log \left(\frac{x}{H\left(1+\rho_{i}^{\prime} d_{i}\right)}\right),
$$

where: $d_{i}$ is a vector of households characteristics and $\theta_{i}^{\prime}, \rho_{i}^{\prime}$ are associated vector coefficients. Note how this de- mographic component not only helps to represent preferences, but it also helps to include the spatial heterogeneity of these preferences, which in the Chilean context is important since significant spatial labor sorting has been identified by the literature (Chacon \& Paredes, 2014). Using the compensated demand, we derive income $\left(\eta_{i e}\right)$, own and crossed-uncompensated $\left(\eta_{i i}\right)$ and compensated $\left(\eta_{i i}^{*}\right)$ price elasticities.

$$
\begin{aligned}
& \eta_{i e}=\left[\left(\beta_{i}+\theta_{i}^{\prime} d_{i}\right) / w_{i}\right]+1 ; \\
& \eta_{i i}=\frac{1}{w_{i}}\left[\left(\beta_{i}+\theta_{i}^{\prime} d_{i}\right)\left(\alpha_{i}+\sum_{k=1}^{m} \gamma_{i k} \log p_{k}\right)\right]-1 ; \\
& \eta_{i i}^{*}=\eta_{i i}+\eta_{i e}{ }^{*} w_{i} .
\end{aligned}
$$

\section{Empirical methodology}

Let us start by discussing the functional form of the hedonic price function. While Rosen (1974) clearly emphasizes the non-linearity of the hedonic price function, the literature has not identified a unique and consensual functional form (see Halvorsen \& Pollakowski (1981) for an initial review). We follow previous literature regarding hedonic prices in Chile and we specify a log-linear functional form where hedonic prices are derived for each housing attribute: ${ }^{2}$

$$
\begin{aligned}
& \ln (P)=\alpha_{0}+\sum_{j} \alpha_{j} Z_{j}+\varepsilon ; \\
& p_{z j}=\partial P / \partial Z_{j}=\exp (\widehat{\ln P}) \alpha_{j},
\end{aligned}
$$

where: $P$ and $Z$ are housing rent price and housing attributes vectors, respectively ${ }^{3}$. Finally, we run the hedonic regression by region, namely 13 regions, for two reasons. First, we want to represent the spatial heterogeneity of preferences due to the diverse climatic and economic conditions throughout Chile that create differences in the supply of housing attributes available and chosen by consumers. Second, the tremendous distances between regions make it impossible to observe the clearing conditions among regional housing markets, which make us believe that differentiated regional hedonic prices would be a more realistic assumption.

Using the hedonic prices indicated in equation (11), we proceed to estimate the simultaneous system of equations defined in equation (6). We use a Non-Linear Seemly Unrelated Regression (NLSUR) and we incorporate the constraints imposed by adding-up, homogeneity, and Slutsky symmetry.

2 See Paredes (2011), Lopez and Aroca (2012) and Paredes and Iturra Rivera (2013).

3 Complete econometric details are not discussed her, but codes can be obtained from the authors upon request. 


\section{Data}

This paper uses data from the Chilean Socioeconomic Household Survey (CASEN - Caracterización SocioEconómica in Spanish) from 2000, 2003, 2006, 2009 and 2011. Although this is a cross-section survey that started in the early 1990s it has only included housing price questions as well as housing and household characteristics since 2000. Having both housing and households' characteristics allows us to control for demographic variables in revealing consumer preferences, a feature that is crucial for our empirical strategy.

Even when the survey includes enough housing attributes, most of them are dummy variables that do not permit the variability to be incorporated in the demand system. Additionally, the survey does not incorporate housing addresses and so we cannot directly control for location. We face both of the aforementioned problems using a similar strategy as in Garcia and Raya (2011). First, instead of using each of the individual housing attributes, we group them into four dimensions. The first dimension is Housing Size (HS), which is the total number of rooms. Secondly, we have Housing Quality (HQ), which groups housing quality variables into an index describing materiality and conservation for floors, walls and ceilings. ${ }^{4}$

The third group is a set of variables such as landline, refrigerator, water heater, washer and computer (which are only available as dummy variables) that were incorporated into an index called Housing Features (HF). To construct this index we tested two main approaches. The first is Factor Analysis in which we reduce 5 housing feature variables into one factor that explains the majority of the underlying variance. The second approach is a weighted average index proposed in Parsons (1986) ${ }^{5}$. Although both resulting indices are consistent and produce robust results, we prefer to include the index based on Factor Analysis in our estimations since its construction and interpretation are more parsimonious. Moreover, results from the Factor Analysis are quite confirmatory since only one factor was retained (positive eigenvalue) and all factor loadings are positive suggesting that the predicted factor will contain most of the information described in the individual variables.

We propose a fourth dimension called Housing Location (HL) but it must be carefully interpreted because of the lack of information about the exact address of each house in the CASEN survey. To overcome this limitation

\footnotetext{
4 This follows the recommendations of the Latin American and Caribbean Demographic Center (CELADE - Centro Latinoamericano y Caribeño de Demografía in Spanish).

5 Please see in the Supplementary Annex A for complete details about the construction and result tables for both Housing Features definitions. Appendix A1 shows the HS computed trough a Factorial Analysis, while A2 shows the weighted average proposed by Parsons (1986). All our results consider the index built by Factorial Analysis, but we use the Parson's index to evaluate the robustness of them.
}

this paper follows the approach used in Garcia and Raya (2011) who countered the same problem using an ingenious strategy. The authors discovered that the second best way of capturing locational effects when the actual location is not available is assuming that the level of schooling of the household head be a satisfactory proxy for a desirable neighborhood. The intuition behind this assumption is that households with higher education levels will enjoy a higher income and hence be able to access houses located in more preferable areas. Garcia and Raya (2011) supports this assumption by including a set of fixed effects at the lowest level of spatial aggregation in the hedonic regressions, and then comparing those coefficients with the education level via a correlation coefficient. Even when this procedure does not explicitly highlight the individual local amenities affecting a particular housing price, these effects should be captured by the coefficients of each dummy. In fact, Garcia and Raya (2011) find a strong correlation (close to 0.9) (p. 5), which is expected since their data is only for Barcelona and hence the disaggregation level is also higher. In our case, we find a weaker correlation (close to 0.4), which is expected since the lowest disaggregation level available is the municipality and more than one small housing market can be contained in a single municipality. Nonetheless, its positive sign is interpreted here as a signal to support our use of the variable "years of schooling" as a proxy for housing location.

Due to changes in variable names and codifications over time, prior to conducting estimations it was necessary to achieve consistency as well as to select only relevant variables and observations. ${ }^{6}$ However, and as noted before, the main attractiveness of the data is that all Chilean regions are represented in the sample for which the 13-regions classification was chosen ${ }^{7}$. This is portrayed in Figure 1 along with the municipality classification.

Finally and using the aforementioned data, a set of additional calculations and filters was created in order to conduct the estimations ${ }^{8}$. Here it is worth noting that we were forced to focus solely on the demand estimations for the renters subsample in this paper since housing prices for owners in 2011 are missing. Although we do not propose an econometric exercise to deal with a potential problem of selection bias, we expect a future paper will include the estimation of the demand systems for both owners and renters, since we acknowledge the importance of

6 Stata scripts for compilation, consistency, and cleaning are available to the reader upon request. Additionally, the Stata format data sets are available at http://observatorio.ministeriodesarrollosocial.gob.cl/casen_obj.php. Used together, the reader should be able to construct the data set used in this paper.

7 Although since 2006 the new regional classification contemplates 15 regions, it was only possible to aggregate the years 2006-2011, leaving 13 regions and 343 municipalities (US counties equivalent)

8 An example of these filters is eliminating observations with missing or null renting price, etc. All filters are also available upon request. 
Table 1. Descriptive analysis for hedonic regression

\begin{tabular}{|l|l|l|l|c|c|c|}
\hline \multicolumn{1}{|c|}{ Variable } & \multicolumn{1}{|c|}{ Description } & min & mean & p50 & max & sd \\
\hline Ln(Rent Price) & Natural logaritm of monthly rent prices in CLP & 9.21 & 11.17 & 11.16 & 12.90 & 0.67 \\
\hline HS & Housing Size: Total number of Rooms in the house & 1.00 & 5.25 & 5.00 & 36.00 & 1.60 \\
\hline HQ & Housing Quality: Index based on floor, walls and ceilings & 0.01 & 0.75 & 0.79 & 1.00 & 0.23 \\
\hline HL & Housing Location: Proxy by years of schooling & 1.00 & 11.44 & 12.00 & 23.00 & 3.70 \\
\hline WasherD & Dummy for Washer Yes=1, No=0 & 0.00 & 0.72 & 1.00 & 1.00 & 0.45 \\
\hline RefrigeratorD & Dummy for Refrigerator Yes=1, No=0 & 0.00 & 0.92 & 1.00 & 1.00 & 0.27 \\
\hline LandlineD & Dummy for Landline Yes=1, No=0 & 0.00 & 0.31 & 0.00 & 1.00 & 0.46 \\
\hline WaterHeaterD & Dummy for Water Heater Yes=1, No=0 & 0.00 & 0.66 & 1.00 & 1.00 & 0.47 \\
\hline ComputerD & Dummy for Computer Yes=1, No=0 & 0.00 & 0.39 & 0.00 & 1.00 & 0.49 \\
\hline Year2003D & Dummy for Year 2003=1, otherwise=0 & 0.00 & 0.18 & 0.00 & 1.00 & 0.39 \\
\hline Year2006D & Dummy for Year 2006=1, otherwise=0 & 0.00 & 0.20 & 0.00 & 1.00 & 0.40 \\
\hline Year2009D & Dummy for Year 2009=1, otherwise=0 & 0.00 & 0.21 & 0.00 & 1.00 & 0.40 \\
\hline Year2011D & Dummy for Year 2011=1, otherwise=0 & 0.00 & 0.25 & 0.00 & 1.00 & 0.43 \\
\hline HouseTypeB & Dummy for Apartment=1, otherwise=0 & 0.00 & 0.12 & 0.00 & 1.00 & 0.33 \\
\hline HouseTypeC & Dummy for Other house type=1, otherwise=0 & 0.00 & 0.02 & 0.00 & 1.00 & 0.14 \\
\hline Zone & Dummy for Zone, Urban=1, Rural=0 & 0.00 & 0.91 & 1.00 & 1.00 & 0.29 \\
\hline
\end{tabular}

Note: 33,733 Observations.
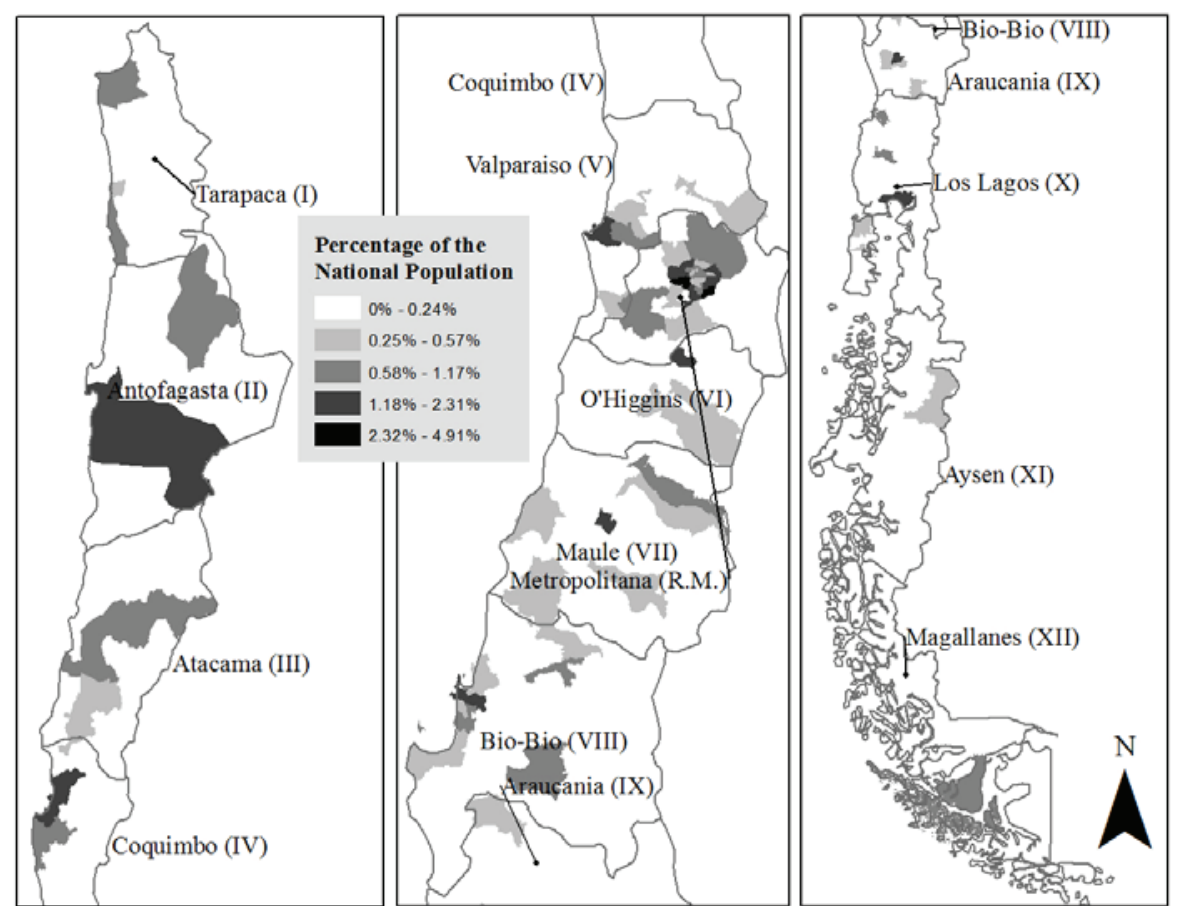

Figure 1. Map of Chile and its regional and communal administrative boundaries

characterizing the two types of consumers. This is not only because of their intrinsic differences on how they evaluate housing choices, but also because recent developments in Chilean housing policy have targeted both groups of consumers.

\section{Empirical analysis}

We begin the empirical analysis with the hedonic regressions and Table 2 shows the estimated coefficients for equation (10). As discussed in the previous section, we estimate this regression for each of the 13 regions portrayed in Figure 1. Given that housing attributes are considered consumption 
Table 2. Hedonic regression with housing feature using factorial analysis Dependent variable: $\log ($ Rent Price)

\begin{tabular}{|c|c|c|c|c|c|c|c|c|c|c|c|c|c|}
\hline Variable & $\begin{array}{c}\text { Tarapacá } \\
\text { (I) }\end{array}$ & $\begin{array}{l}\text { Antofa- } \\
\text { gasta (II) }\end{array}$ & $\begin{array}{c}\text { Atacama } \\
\text { (III) }\end{array}$ & $\begin{array}{c}\text { Coquimbo } \\
\text { (IV) }\end{array}$ & $\begin{array}{c}\text { Valparaiso } \\
(\mathrm{V})\end{array}$ & $\begin{array}{l}\text { O'Higgins } \\
\text { (VI) }\end{array}$ & $\begin{array}{c}\text { Maule } \\
\text { (VII) }\end{array}$ & $\begin{array}{l}\text { Biobio } \\
\text { (VIII) }\end{array}$ & $\begin{array}{c}\text { Araucanía } \\
\text { (IX) }\end{array}$ & $\begin{array}{c}\text { Los Lagos } \\
\text { (X) }\end{array}$ & Aysén (XI) & $\begin{array}{l}\text { Magallanes } \\
\quad \text { (XII) }\end{array}$ & $\begin{array}{l}\text { Metro- } \\
\text { politana } \\
\text { (R.M) }\end{array}$ \\
\hline HS & $\begin{array}{c}0.0525 \\
(0.0124)\end{array}$ & $\begin{array}{c}0.0437 \\
(0.0143)\end{array}$ & $\begin{array}{c}0.0912 \\
(0.0189)\end{array}$ & $\begin{array}{c}0.129 \\
(0.0135)\end{array}$ & $\begin{array}{c}0.127 \\
(0.0102)\end{array}$ & $\begin{array}{c}0.138 \\
(0.01000)\end{array}$ & $\begin{array}{c}0.127 \\
(0.0117)\end{array}$ & $\begin{array}{c}0.112 \\
(0.0126)\end{array}$ & $\begin{array}{c}0.130 \\
(0.0183)\end{array}$ & $\begin{array}{c}0.0686 \\
(0.00858)\end{array}$ & $\begin{array}{c}0.0701 \\
(0.0173)\end{array}$ & $\begin{array}{c}0.0762 \\
(0.0209)\end{array}$ & $\begin{array}{c}0.0891 \\
(0.00626)\end{array}$ \\
\hline HQ & $\begin{array}{c}0.751 \\
(0.280)\end{array}$ & $\begin{array}{r}2.322 \\
(0.403)\end{array}$ & $\begin{array}{c}1.229 \\
(0.344)\end{array}$ & $\begin{array}{c}0.960 \\
(0.221)\end{array}$ & $\begin{array}{c}0.407 \\
(0.159)\end{array}$ & $\begin{array}{c}0.702 \\
(0.140)\end{array}$ & $\begin{array}{c}1.042 \\
(0.171)\end{array}$ & $\begin{array}{r}0.752 \\
(0.208)\end{array}$ & $\begin{array}{r}0.816 \\
(0.182)\end{array}$ & $\begin{array}{c}1.312 \\
(0.157)\end{array}$ & $\begin{array}{c}0.690 \\
(0.332)\end{array}$ & $\begin{array}{c}0.733 \\
(0.296)\end{array}$ & $\begin{array}{c}0.920 \\
(0.0984)\end{array}$ \\
\hline $\mathrm{HF}$ & $\begin{array}{c}0.263 \\
(0.0324)\end{array}$ & $\begin{array}{c}0.258 \\
(0.0340)\end{array}$ & $\begin{array}{c}0.223 \\
(0.0461)\end{array}$ & $\begin{array}{c}0.248 \\
(0.0278)\end{array}$ & $\begin{array}{c}0.224 \\
(0.0200)\end{array}$ & $\begin{array}{c}0.175 \\
(0.0245)\end{array}$ & $\begin{array}{c}0.279 \\
(0.0245)\end{array}$ & $\begin{array}{c}0.229 \\
(0.0315)\end{array}$ & $\begin{array}{c}0.279 \\
(0.0387)\end{array}$ & $\begin{array}{c}0.209 \\
(0.0230)\end{array}$ & $\begin{array}{c}0.198 \\
(0.0443)\end{array}$ & $\begin{array}{c}0.184 \\
(0.0415)\end{array}$ & $\begin{array}{c}0.208 \\
(0.0124)\end{array}$ \\
\hline $\mathrm{HL}$ & $\begin{array}{c}0.0299 \\
(0.00627)\end{array}$ & $\begin{array}{c}0.0286 \\
(0.00753)\end{array}$ & $\begin{array}{c}0.0373 \\
(0.00788)\end{array}$ & $\begin{array}{c}0.0387 \\
(0.00428)\end{array}$ & $\begin{array}{c}0.0417 \\
(0.00307)\end{array}$ & $\begin{array}{c}0.0397 \\
(0.00436)\end{array}$ & $\begin{array}{c}0.0398 \\
(0.00428)\end{array}$ & $\begin{array}{c}0.0464 \\
(0.00542)\end{array}$ & $\begin{array}{c}0.0291 \\
(0.00621)\end{array}$ & $\begin{array}{c}0.0280 \\
(0.00372)\end{array}$ & $\begin{array}{c}0.0328 \\
(0.00638)\end{array}$ & $\begin{array}{c}0.0392 \\
(0.00909)\end{array}$ & $\begin{array}{c}0.0438 \\
(0.00193)\end{array}$ \\
\hline Year2003D & $\begin{array}{c}-0.144 \\
(0.0686)\end{array}$ & $\begin{array}{c}0.0460 \\
(0.0653) \\
\end{array}$ & $\begin{array}{l}-0.0595 \\
(0.0785)\end{array}$ & $\begin{array}{l}-0.0187 \\
(0.0553)\end{array}$ & $\begin{array}{l}-0.0180 \\
(0.0294)\end{array}$ & $\begin{array}{l}-0.0549 \\
(0.0477)\end{array}$ & $\begin{array}{l}-0.0676 \\
(0.0449)\end{array}$ & $\begin{array}{l}-0.0203 \\
(0.0359)\end{array}$ & $\begin{array}{c}-0.00519 \\
(0.0686)\end{array}$ & \begin{tabular}{|c|}
-0.00676 \\
$(0.0473)$ \\
\end{tabular} & $\begin{array}{c}0.0789 \\
(0.0730) \\
\end{array}$ & $\begin{array}{c}-0.0681 \\
(0.111)\end{array}$ & $\begin{array}{c}-0.00406 \\
(0.0187)\end{array}$ \\
\hline Year2 & $\begin{array}{c}-0.102 \\
(0.0714)\end{array}$ & $\begin{array}{c}0.0728 \\
(0.0707)\end{array}$ & $\begin{array}{l}-0.0221 \\
(0.0766)\end{array}$ & $\begin{array}{c}0.0392 \\
(0.0566)\end{array}$ & $\begin{array}{l}-0.0133 \\
(0.0289)\end{array}$ & $\begin{array}{c}-0.00195 \\
(0.0480)\end{array}$ & $\begin{array}{l}-0.0480 \\
(0.0396)\end{array}$ & $\begin{array}{l}0.00120 \\
(0.0318)\end{array}$ & $\begin{array}{c}-0.128 \\
(0.0544)\end{array}$ & $\begin{array}{l}0.00370 \\
(0.0470)\end{array}$ & $\begin{array}{c}0.143 \\
(0.0697)\end{array}$ & $\begin{array}{c}-0.0560 \\
(0.109)\end{array}$ & $\begin{array}{c}0.0293 \\
(0.0196)\end{array}$ \\
\hline Year2 & $\begin{array}{l}-0.0501 \\
(0.0713)\end{array}$ & $\begin{array}{c}0.373 \\
(0.0722)\end{array}$ & $\begin{array}{c}0.0993 \\
(0.0838)\end{array}$ & $\begin{array}{c}0.198 \\
(0.0543)\end{array}$ & $\begin{array}{c}0.118 \\
(0.0308)\end{array}$ & $\begin{array}{c}0.128 \\
(0.0444)\end{array}$ & $\begin{array}{c}0.0613 \\
(0.0446)\end{array}$ & $\begin{array}{c}0.0521 \\
(0.0440)\end{array}$ & $\begin{array}{l}-0.0102 \\
(0.0540)\end{array}$ & $\begin{array}{c}0.158 \\
(0.0490)\end{array}$ & $\begin{array}{c}0.371 \\
(0.0678)\end{array}$ & $\begin{array}{l}0.0646 \\
(0.104)\end{array}$ & $\begin{array}{c}0.159 \\
(0.0200)\end{array}$ \\
\hline Year2011D & $\begin{array}{l}-0.0424 \\
(0.0912)\end{array}$ & $\begin{array}{c}0.114 \\
(0.0878)\end{array}$ & $\begin{array}{c}0.234 \\
(0.0990)\end{array}$ & $\begin{array}{l}-0.0193 \\
(0.0670)\end{array}$ & $\begin{array}{c}0.0863 \\
(0.0509)\end{array}$ & $\begin{array}{c}0.134 \\
(0.0561)\end{array}$ & $\begin{array}{c}-0.209 \\
(0.0604)\end{array}$ & $\begin{array}{c}-0.00170 \\
(0.0743)\end{array}$ & $\begin{array}{c}-0.223 \\
(0.0886)\end{array}$ & $\begin{array}{l}-0.515 \\
(0.106)\end{array}$ & $\begin{array}{c}0.174 \\
(0.128)\end{array}$ & $\begin{array}{l}0.0362 \\
(0.181)\end{array}$ & $\begin{array}{c}0.0430 \\
(0.0281)\end{array}$ \\
\hline HouseTypeB & $\begin{array}{c}-0.168 \\
(0.0702)\end{array}$ & $\begin{array}{c}0.0344 \\
(0.0699)\end{array}$ & $\begin{array}{l}-0.394 \\
(0.141)\end{array}$ & $\begin{array}{c}0.370 \\
(0.107)\end{array}$ & $\begin{array}{c}0.0485 \\
(0.0392)\end{array}$ & $\begin{array}{c}-0.182 \\
(0.0396)\end{array}$ & $\begin{array}{c}-0.186 \\
(0.0836)\end{array}$ & $\begin{array}{c}0.193 \\
(0.0523)\end{array}$ & $\begin{array}{c}0.0353 \\
(0.0647)\end{array}$ & $\begin{array}{c}-0.221 \\
(0.0758)\end{array}$ & $\begin{array}{c}0.125 \\
(0.198)\end{array}$ & $\begin{array}{l}-0.359 \\
(0.156)\end{array}$ & $\begin{array}{c}0.110 \\
(0.0198)\end{array}$ \\
\hline HouseTypeC & $\begin{array}{c}-0.0136 \\
(0.103)\end{array}$ & $\begin{array}{c}0.729 \\
(0.238)\end{array}$ & $\begin{array}{c}0.121 \\
(0.160)\end{array}$ & $\begin{array}{c}0.346 \\
(0.195)\end{array}$ & $\begin{array}{c}0.282 \\
(0.144)\end{array}$ & $\begin{array}{l}0.0248 \\
(0.165)\end{array}$ & $\begin{array}{c}0.367 \\
(0.108) \\
\end{array}$ & $\begin{array}{l}0.0116 \\
(0.124)\end{array}$ & $\begin{array}{c}0.182 \\
(0.162)\end{array}$ & $\begin{array}{r}0.0704 \\
(0.0995)\end{array}$ & $\begin{array}{c}0.290 \\
(0.159)\end{array}$ & $\begin{array}{c}0.110 \\
(0.160) \\
\end{array}$ & $\begin{array}{c}0.135 \\
(0.0558)\end{array}$ \\
\hline Zone & $\begin{array}{c}-0.0441 \\
(0.112)\end{array}$ & $\begin{array}{l}-0.689 \\
(0.141)\end{array}$ & $\begin{array}{l}-0.237 \\
(0.135)\end{array}$ & $\begin{array}{c}0.131 \\
(0.0897)\end{array}$ & $\begin{array}{c}0.119 \\
(0.0850)\end{array}$ & $\begin{array}{c}0.112 \\
(0.0587)\end{array}$ & $\begin{array}{l}-0.00417 \\
(0.0682)\end{array}$ & $\begin{array}{c}0.0284 \\
(0.0873)\end{array}$ & $\begin{array}{c}0.000364 \\
(0.0770)\end{array}$ & $\begin{array}{c}-0.149 \\
(0.0544)\end{array}$ & $\begin{array}{l}0.0706 \\
(0.123)\end{array}$ & $\begin{array}{l}-0.517 \\
(0.278)\end{array}$ & $\begin{array}{c}0.0476 \\
(0.0648)\end{array}$ \\
\hline Constant & $\begin{array}{c}9.883 \\
(0.141) \\
\end{array}$ & $\begin{array}{r}9.109 \\
(0.209)\end{array}$ & $\begin{array}{c}8.990 \\
(0.195) \\
\end{array}$ & $\begin{array}{r}8.568 \\
(0.121) \\
\end{array}$ & $\begin{array}{c}9.190 \\
(0.0814) \\
\end{array}$ & $\begin{array}{c}8.891 \\
(0.0894) \\
\end{array}$ & $\begin{array}{c}8.575 \\
(0.0706) \\
\end{array}$ & $\begin{array}{c}8.993 \\
(0.0630)\end{array}$ & $\begin{array}{r}9.115 \\
(0.113)\end{array}$ & $\begin{array}{c}9.805 \\
(0.0701) \\
\end{array}$ & $\begin{array}{r}9.614 \\
(0.108)\end{array}$ & $\begin{array}{c}10.32 \\
(0.316) \\
\end{array}$ & $\begin{array}{c}9.202 \\
(0.0692) \\
\end{array}$ \\
\hline $\begin{array}{l}\mathrm{N} \\
\mathrm{R}-\mathrm{sq}\end{array}$ & $\begin{array}{l}2029 \\
0.367\end{array}$ & $\begin{array}{l}1678 \\
0.509\end{array}$ & $\begin{array}{c}979 \\
0.417 \\
\end{array}$ & $\begin{array}{l}1132 \\
0.583\end{array}$ & $\begin{array}{l}3917 \\
0.452\end{array}$ & $\begin{array}{l}1903 \\
0.510\end{array}$ & $\begin{array}{l}2168 \\
0.571\end{array}$ & $\begin{array}{l}4091 \\
0.553\end{array}$ & $\begin{array}{l}1925 \\
0.532\end{array}$ & $\begin{array}{l}3164 \\
0.488\end{array}$ & $\begin{array}{c}930 \\
0.499\end{array}$ & $\begin{array}{c}591 \\
0.486\end{array}$ & $\begin{array}{l}9204 \\
0.498\end{array}$ \\
\hline
\end{tabular}

Standard errors in parentheses

goods, we expect positive coefficients to be associated with each one of the four characteristics. Besides paying attention to the coefficient signs, we follow the literature on hedonic prices which suggest we take advantage of the log-linear form which is used here to discuss the coefficients as pseudo-elasticities (Cropper, Deck, \& McConnell, 1988). Housing Size (HS) shows a positive and significant coefficient in each region implying that larger houses have higher renting prices. In particular, HS ranges from $4.37 \%$ (I Region of Tarapacá) to 13.8\% (IV Region de O'Higgins). This variability of pseudoelasticity across regions can be understood as initial evidence to support our hypothesis of spatial heterogeneity. The rest of the housing attributes also show a positive coefficient, with their magnitudes differing among themselves and across regions. For example, Housing Quality (HQ) is the highest coefficient for all regions, while our proxy of Housing Location (HL) is the lowest coefficient, with both housing attributes statistically significant in all regions.

Nevertheless, as the previous analysis and literature highlight, real economic meaning must be derived from the estimation of a system of equations Rosen (1974) instead of only using hedonic regressions. An empirical reason to not rely on hedonic regressions alone is the fact that significance levels vary across regions, which is presumably due to different sample sizes. While the Metropolitan Region of Santiago consists of $42 \%$ of the total population, regions such as Aysén (XI) make up less than 1\% (see Figure 1). This fact has direct consequences on sample sizes obtained from CASEN where the Aysén Region (XI) sample size accounts only for $10 \%$ of the Metropolitan Region sample size (930 versus 9204). Albeit these differences in sample sizes and significance levels, the estimated coefficients for housing attributes are significant for almost all regions.

Our data posed an additional empirical particularity given that we are using pooled data, i.e. different crosssection samples collected over time, for which we included a dummy variable by year to control for temporal shocks associated with housing markets (Wooldridge, 2012). Estimated coefficients show that yearly effects are significant only for some regions, which supports the theory that a housing market's structural equilibriums differ among regions. Additionally, the fact that yearly effects are not significant for all regions allows us to eliminate the need for varying housing attributes' coefficients per year. 
Finally, there were two additional empirical issues that are worth mentioning. First, we controlled for the type of housing. The benchmark category is a house, while House Type B (See Table 1) indicates an apartment and House Type C (See Table 1) indicates a shelter with a lower structural quality than houses and apartments. The estimated coefficients again show the expected signs: apartments have, on average, lower prices than houses. Second and similar to housing type, rural zone plays the role of an important control variable. We expected that rural housing does not capture the economics of agglomeration derived from large urban areas and consequently would have lower prices (Combes, Duranton, \& Gobillon, 2011). Our estimations do not support this hypothesis for each region since in most cases the coefficients are not significant implying an unclear effect of this variable. Even when we are not primarily concerned about these control variables, we accept that they are factors that must be controlled for. As a result, our control strategy generates an r-squared between 0.367 and 0.583 which is a good level of fit for micro data such as households.

Once we checked the empirical performance of the hedonic regressions, we used equation (11) to generate hedonic prices for each observation. Table 3 portrays descriptive statistics for these hedonic prices. HQ is the most expensive attribute on average (8.84) followed by HF (7.79), then HS (6.97) and finally HL (5.93). Once hedonic prices were calculated, we estimated the demand system specified in equation (6). Table 4 shows the parameters obtained through Non-Linear SUR. As can be seen, these parameters can hardly be discussed given the high nonlinearity of these functions. However, they are of crucial relevance in estimating our elasticities defined by equations (7), (8) and (9). Table 5 shows income elasticities for different demographic components evaluated at median values. Moving from left to right, the results show that HQ and HF are considered luxury goods. This implies that consumers will spend relatively more on HQ and HF as their income increases. Conversely, HS and HL are perceived as normal goods, also understood as basic necessities, implying that their consumption changes less than proportionally to response to income variations. Finally, we note that all the elasticities are bigger than zero, which rules out the existence of inferior goods, i.e. all housing attributes show increases in consumption as income increases.

Table 4. AIDS for Housing Attributes (AIDS-HA) parameter estimates

\begin{tabular}{|l|c|c|}
\hline & $\begin{array}{c}\text { Without } \\
\text { Demographics }\end{array}$ & $\begin{array}{c}\text { With } \\
\text { Demographics }\end{array}$ \\
\hline$\alpha_{1}$ & 0.352 & 0.354 \\
\hline$\alpha_{2}$ & -0.0371 & -0.0294 \\
\hline$\alpha_{3}$ & 0.198 & 0.184 \\
\hline$\beta_{1}$ & -0.0215 & -0.0121 \\
\hline$\beta_{2}$ & 0.0575 & 0.0687 \\
\hline$\beta_{3}$ & 0.0301 & 0.00402 \\
\hline$\gamma_{11}$ & 0.183 & 0.178 \\
\hline$\gamma_{12}$ & -0.0817 & -0.0798 \\
\hline$\gamma_{13}$ & -0.0379 & -0.0348 \\
\hline$\gamma_{22}$ & 0.200 & 0.202 \\
\hline$\gamma_{23}$ & -0.0481 & -0.0532 \\
\hline$\gamma_{33}$ & 0.115 & 0.119 \\
\hline$\rho_{1}$ & -0.0221 & -0.0270 \\
\hline$\theta_{11}$ & -0.00914 & -0.00942 \\
\hline$\theta_{21}$ & 0.00595 & 0.00693 \\
\hline$\theta_{31}$ & -0.000726 & -0.00146 \\
\hline Constant & -0.000726 & -0.00146 \\
\hline $\mathrm{N}$ & 33733 & 33733 \\
\hline & & \\
\hline & & 0.001 \\
\hline
\end{tabular}

*** All variables are significant at $\mathrm{p}<0.001$

Table 3. Descriptive statistics for Almost Ideal Demand System

\begin{tabular}{|l|l|c|c|c|c|c|}
\hline \multicolumn{1}{|c|}{ Variable } & & $\min$ & mean & p50 & max & sd \\
\hline HS & Housing Size & 1.00 & 5.25 & 5.00 & 36.00 & 1.60 \\
\hline HQ & Housing Quality & 0.01 & 0.75 & 0.79 & 1.00 & 0.23 \\
\hline HF & Housing Features & 0.44 & 1.66 & 1.73 & 2.66 & 0.67 \\
\hline HL & Housing Location & 1.00 & 11.44 & 12.00 & 23.00 & 3.70 \\
\hline z1 & Household Size & 1.00 & 3.51 & 3.00 & 15.00 & 1.55 \\
\hline s_HS & Share of expenditure in HS & 0.01 & 0.26 & 0.25 & 0.71 & 0.10 \\
\hline s_HQ & Share of expenditure in HL & 0.01 & 0.33 & 0.33 & 0.84 & 0.13 \\
\hline s_HF & Share of expenditure in HF & 0.04 & 0.18 & 0.19 & 0.54 & 0.06 \\
\hline s_HL & Share of expenditure in HL & 0.01 & 0.22 & 0.23 & 0.67 & 0.07 \\
\hline $\operatorname{lnp1}$ & $\log$ (Hedonic price for HS) & 6.97 & 8.87 & 8.89 & 11.30 & 0.50 \\
\hline $\operatorname{lnp2}$ & $\log$ (Hedonic price for HQ) & 8.84 & 11.08 & 11.09 & 13.69 & 0.67 \\
\hline $\ln 33$ & $\log$ (Hedonic price for HF) & 7.79 & 9.74 & 9.76 & 11.54 & 0.50 \\
\hline $\ln 4$ & $\log$ (Hedonic price for HL) & 5.93 & 7.97 & 7.99 & 10.06 & 0.54 \\
\hline $\ln w$ & $\log$ (Total expenditure in 4 Attributes) & 8.23 & 11.90 & 11.96 & 14.70 & 0.76 \\
\hline
\end{tabular}

Note: 33,733 Observations. 
Table 5. Income elasticities

\begin{tabular}{|l|c|c|c|c|c|c|c|c|c|c|c|c|c|c|}
\hline \multicolumn{4}{|c|}{ AIDSHA without Demographics } & \multicolumn{4}{c|}{ AIDSHA with Demographics } \\
\hline \multicolumn{4}{|c|}{ Household Size $=3$} & \multicolumn{4}{c|}{ Small Families: Household Size $\leq 2$} & \multicolumn{5}{c|}{ Big Families: Household Size $\geq 4$} \\
\hline Elasticity & $H S$ & $H Q$ & $H F$ & $H L$ & Elasticity & $H S$ & $H Q$ & $H F$ & $H L$ & Elasticity & $H S$ & $H Q$ & $H F$ & $H L$ \\
\hline Income & 0.8081 & 1.2245 & $\mathbf{1 . 1 5 0 2}$ & $\mathbf{0 . 7 5 6 6}$ & Income & $\mathbf{0 . 8 3 7 6}$ & $\mathbf{1 . 2 0 3 2}$ & $\mathbf{1 . 1 5 4 8}$ & $\mathbf{0 . 7 4 4 8}$ & Income & $\mathbf{0 . 7 8 0 3}$ & $\mathbf{1 . 2 4 5 9}$ & $\mathbf{1 . 1 4 5 1}$ & $\mathbf{0 . 7 6 8 1}$ \\
\hline CI-lower & 0.8070 & 1.2245 & 1.1497 & 0.7562 & CI-lower & 0.8361 & 1.2013 & 1.1538 & 0.7426 & CI-lower & 0.7797 & 1.2452 & 1.1447 & 0.7641 \\
\hline CI-upper & 0.8092 & 1.2245 & 1.1507 & 0.7571 & CI-upper & 0.8391 & 1.2052 & 1.1558 & 0.7469 & CI-upper & 0.7809 & 1.2467 & 1.1456 & 0.7721 \\
\hline
\end{tabular}

Note: Confidence Intervals calculated using bootstrap with 300 repetitions.

As we move to the right of Table 5, we explore how these elasticities vary from small households to larger households. Results support the presence of small differences between elasticities for smaller (less than or equal to 2) and larger (greater than or equal to 4) household sizes. However, in spite of these small differences found, the estimated confidence intervals indicate they are significant. Moreover, is important to note that our classification of housing attributes as basic necessities (HS and HL) and as luxuries (HQ and HF) is robust regardless of household size. Although this point will be discussed with more detail in our conclusions, these results constitute a relevant piece of evidence in claiming that continuous increases in income without tackling Chile's income inequality will result in continuous increases in the demand of housing quality and housing features, but only for the more accommodated sectors. This result has important policy implications as it highlights that being oblivious to consumer preferences in housing demand might result in widening inequalities, since income increases have different effects depending on the household's economic situation.

After defining HQ and HF as luxury goods, we proceed to detect what attributes present high or low elasticity against price variations. Tables 6 and 7 report uncompensated and compensated price elasticities, respectively ${ }^{9}$. All housing attributes behave according to the well-known Law of Demand, i.e. consumers decrease their consumption as the price of these attributes rises, but there are differences in the magnitudes. Generally speaking, both tables indicate than HS and HL seem to be price-inelastic goods. This implies that consumers are less willing to sacrifice size and location even if the price increases when compared to other housing attributes. This result is in accordance with the aforementioned income elasticities since for those attributes classified as luxuries (i.e. non-easily affordable) consumers are much more elastic to price variations, whereas for those attributes classified as necessities or basic goods (i.e. more affordable), price elasticities are higher, which confirms their status of necessities.

9 The only difference between both elasticities is the incorporation of income effects.
Table 6. Uncompensated Price Elasticities

\begin{tabular}{|l|c|c|c|c|}
\hline \multicolumn{5}{|c|}{ Household Size $=3$} \\
\hline & HS & HQ & HF & HL \\
\hline HS & $\mathbf{- 0 . 2 4 2 2}$ & -0.2394 & -0.1069 & -0.2196 \\
\hline CI-lower & -0.2434 & -0.2401 & -0.1071 & -0.2198 \\
\hline CI-upper & -0.2411 & -0.2386 & -0.1066 & -0.2194 \\
\hline HQ & -0.2876 & $-\mathbf{0 . 4 9 8 9}$ & -0.1923 & -0.2457 \\
\hline CI-lower & -0.2885 & -0.4990 & -0.1931 & -0.2474 \\
\hline CI-upper & -0.2867 & -0.4989 & -0.1914 & -0.2441 \\
\hline HF & -0.2336 & -0.3226 & $-\mathbf{0 . 4 1 1 8}$ & -0.1822 \\
\hline CI-lower & -0.2339 & -0.3242 & -0.4143 & -0.1823 \\
\hline CI-upper & -0.2334 & -0.3209 & -0.4093 & -0.1822 \\
\hline HL & -0.2370 & -0.2118 & -0.0782 & $-\mathbf{0 . 2 2 9 6}$ \\
\hline CI-lower & -0.2371 & -0.2120 & -0.0784 & -0.2312 \\
\hline CI-upper & -0.2368 & -0.2117 & -0.0781 & -0.2280 \\
\hline
\end{tabular}

Note: Confidence Intervals calculated using bootstrap with 300 repetitions.

Table 7. Compensated Price Elasticities

\begin{tabular}{|l|c|c|c|c|}
\hline \multicolumn{5}{|l}{ Household Size $=3$} \\
\hline & $\boldsymbol{H S}$ & HQ & HF & HL \\
\hline HS & $\mathbf{- 0 . 0 3 6 4}$ & -0.0336 & 0.0990 & -0.0138 \\
\hline CI-lower & -0.0388 & -0.0338 & 0.0967 & -0.0159 \\
\hline CI-upper & -0.0341 & -0.0333 & 0.1012 & -0.0117 \\
\hline HQ & 0.1236 & $-\mathbf{0 . 0 8 7 7}$ & 0.2190 & 0.1655 \\
\hline CI-lower & 0.1169 & -0.0880 & 0.2176 & 0.1634 \\
\hline CI-upper & 0.1303 & -0.0874 & 0.2204 & 0.1676 \\
\hline HF & -0.0199 & -0.1089 & $-\mathbf{0 . 1 9 8 1}$ & 0.0315 \\
\hline CI-lower & -0.0220 & -0.1093 & -0.1982 & 0.0312 \\
\hline CI-upper & -0.0178 & -0.1084 & -0.1979 & 0.0318 \\
\hline HL & -0.0677 & -0.0426 & 0.0910 & $-\mathbf{0 . 0 6 0 4}$ \\
\hline CI-lower & -0.0680 & -0.0448 & 0.0905 & -0.0619 \\
\hline CI-upper & -0.0675 & -0.0403 & 0.0915 & -0.0589 \\
\hline
\end{tabular}

Note: Confidence Intervals calculated using bootstrap with 300 repetitions.

Finally, Figure 2 presents income elasticity estimates at the regional level for each housing attribute. Although they are visually non-distinguishable in most cases, these estimations include confidence intervals displayed as continuous areas. Indeed, the fact that the error areas are 

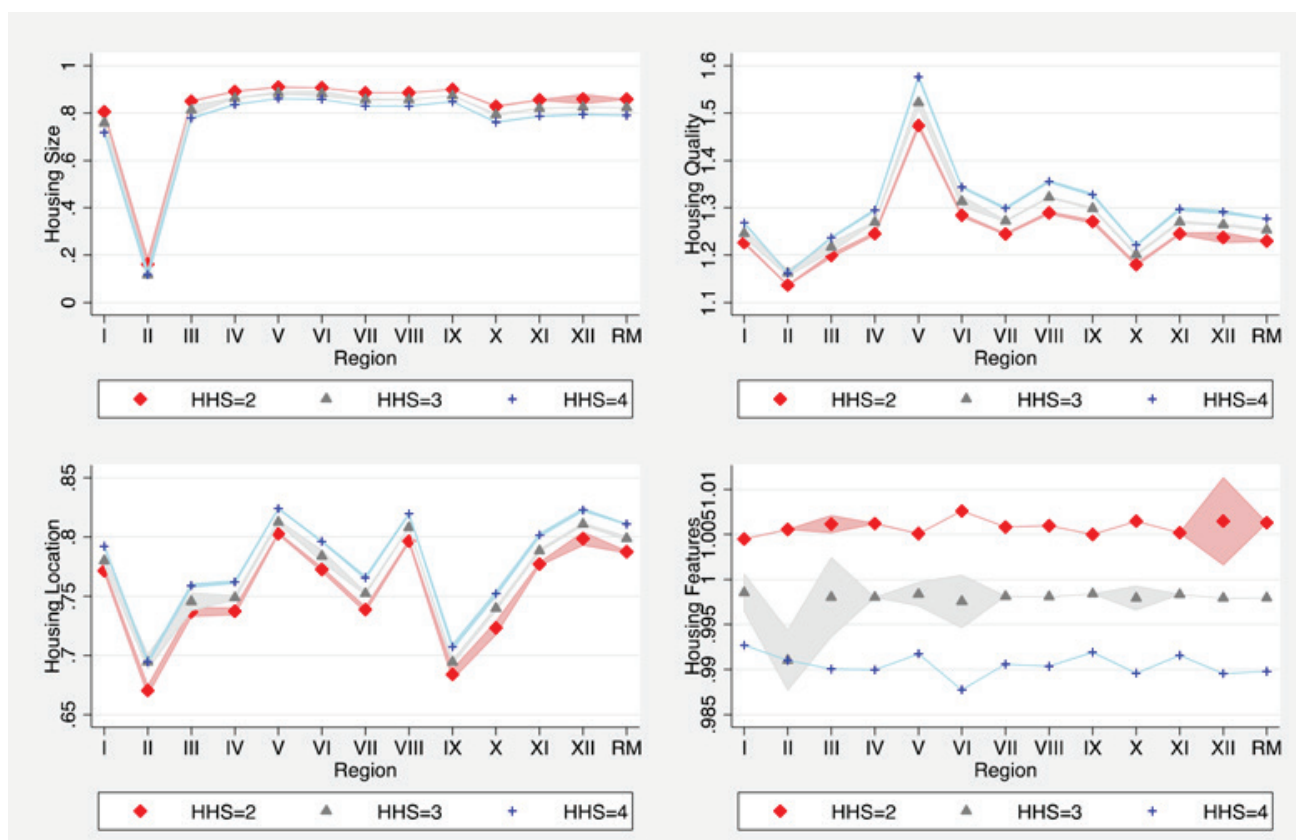

Note: Areas represent standard errors calculated by bootstrap 300 rep

Figure 2. Regional income elasticities for housing attributes

quite close to the point estimates provides further reassurance of the existence of spatial heterogeneity in the way households react to income changes.

In the case of Housing Size, there is not enough empirical evidence to confirm our expectations regarding regional heterogeneity. The figures show how HS income elasticities differ only marginally across regions with the exception of the Antofagasta Region (II). However, a feasible explanation about this difference is related to the markedly higher housing prices in this region which is found in Paredes (2011) and Paredes and Iturra Rivera (2013). We suspect that the particularly high housing demand in the Antofagasta region is pushing prices up resulting in a significant reduction in the income elasticity for this region. Although this seems to be a stylized fact for the Antofagasta region, we accept that we do not have more evidence to explore this issue in detail and so we must leave this for future research.

Figure 2 also portrays regional income elasticities for all Chilean regions and their differences across household sizes. Consistent with the national results discussed previously, smaller households have higher income elasticities than larger households. This result is also robust across regions since the different households' estimations are monotonically higher as household size increases. In summary, the results in this section suggest the presence of stronger spatial heterogeneity for Housing Quality and Housing Location.

\section{Conclusions}

Latin America and Chile have scarce scientific research regarding the economic valuation of housing attributes.
In particular, we believe that we have shown enough evidence to claim that Chile and those countries following its developments in housing policy need to account for the demand of housing attributes. As argued before, this information is crucial when designing housing policy because it provides a more complete picture of the way a household values housing attributes and the effect that changes in prices and income would have on their demand. Moreover, high price spatial differentials raise concerns about how consumers react to price changes among regional markets from national housing programs.

In particular, we find that Housing Quality and Housing Features are considered luxury goods, implying that these goods are consumed in a higher proportional variation to income increments. Consequently, our results suggest that low-income families will be mainly concerned about Housing Quality and Features only if their income rises. Conversely, Housing Size and Housing Location are necessity goods (and price inelastic), implying that both characteristics are highly valuable to consumers and that they are willing to pay for them even when facing price shocks. Our empirical evidence is significant for each region of Chile.

Our results are interesting for policy makers in at least two areas. First, housing policy should be focused on those housing attributes with high price elasticity. The reason behind this suggestion lies on the fact that if everything else remains constant (including Chile's wide income inequality), income and price shocks would have a greater effect on those households with fewer options to modify their consumption (i.e. high price elasticity), a precarious situation for poorer households. In this context, Housing Size and Housing Location should be attributes 
with higher priority when developing housing investments financed by public projects. Regarding Housing Size, we claim that new housing projects must not be necessary focused on quantity, namely a large number of new homes with a small size, but rather new housing projects should provide larger houses even if it means offering less of them. In relation to Housing Location, new projects must be carried out in areas with high spatial connection within cities. Our results are similar to those found by Greene and Ortúzar (2002), who point that dwellers seem to value more those attributes that they lack of, and in particular households with small houses and bad location value more bigger houses and better location (p. 76).

A potentially new public policy should focus on balancing households' needs of better location and size. Even when we accept that our results are not the final word in this political scenario, we trust that our research has at least provided new insights that might initiate a new outline of public policy in which the consumer's preference are at the core of the interventions.

\section{Acknowledgments}

This work was supported by the Lincoln Institute of Land Policy, No. LDP091913. Any opinions, findings and conclusions are those of the authors and do not necessarily reflect the views of the Lincoln Institute of Land Policy. The authors would like to thank to the participants of the research seminar "Land Policy and Urban Development in Latin America" as well as Leonardo Bonilla, Kathy Baylis, Edward Feser, Geoffrey Hewings and the members of the Regional Economics Applications Laboratory of the University of Illinois at Urbana-Champaign for their useful comments and suggestions.

\section{References}

Awan, K., Odling-Smee, J. C., \& Whitehead, C. M. E. (1982). Household attributes and the demand for private rental housing. Economica, 49(194), 183-119.

https://doi.org/10.2307/2553306

Arimah, B. (1992). Hedonic prices and the demand for housing attributes in a third world city: the case of Ibadan, Nigeria. Urban Studies, 29(5), 639-651. https://doi.org/10.1080/00420989220080601

Caldera Sánchez, A. (2012). Building blocks for a better functioning housing market in Chile. OECD Economics Department Working Papers, No. 943. OECD Publishing.

Chacon, S., \& Paredes, D. (2014). Spatial income inequality in Chile and the rol of spatial labor sorting. Ideas.Repec.org. Retrieved from http://ideas.repec.org/p/cat/dtecon/dt201315.html

Chamorro, C. (2013). Politica habitacional en Chile: historia, resultados y desafíos. Documento de trabajo de La Cámara Chilena de la Construcción. Retrieved from http://www.cchc. cl/wp-content/uploads/2013/05/DT72-Pol\%C3\%ADticaHabitacional.pdf

Cheshire, P., \& Sheppard, S. (1998). Estimating the demand for housing, land, and neighbourhood characteristics. Oxford Bulletin of Economics and Statistics, 60(3), 357-382. https://doi.org/10.1111/1468-0084.00104
Combes, P. P., Duranton, G., \& Gobillon, L. (2011). The identification of agglomeration economies. Journal of Economic Geography, 11(2), 253-266. https://doi.org/10.1093/jeg/lbq038

Cropper, M. L., Deck, L. B., \& McConnell, K. E. (1988). On the choice of funtional form for hedonic price functions. Review of Economics and Statistics, 70(4), 668-675.

https://doi.org/10.2307/1935831

Deaton, A., \& Muellbauer, J. (1980). An almost ideal demand system. American Economic Review, 70(3), 312-326.

Follain, J. R., \& Jimenez, E. (1985). The demand for housing characteristics in developing countries. Urban Studies, 22(5), 421-432. https://doi.org/10.1080/00420988520080731

Garcia, J., \& Raya, J. M. (2011). Price and income elasticities of demand for housing characteristics in the city of Barcelona. Regional Studies, 45(5), 597-608.

https://doi.org/10.1080/00343401003713381

Gilbert, A. (2002). Power, ideology and the Washington consensus: the development and spread of Chilean housing policy. Housing Studies, 17(2), 305-324. https://doi.org/10.1080/02673030220123243

Gilbert, A. (2011). La vivienda en América Latina: revisando estrategias [Housing in Latin America: Reviced strategies]. Revista de Ingeniería, 35, 48-50.

Gilbert, A. G. (2014). Free housing for the poor: an effective way to address poverty?. Habitat International, 41, 253-261. https://doi.org/10.1016/j.habitatint.2013.08.009

Greene, M., \& Ortúzar, J. de D. (2002). Willingness to pay for social housing attributes: a case study from Chile. International Planning Studies, 7(1), 55-87. https://doi.org/10.1080/13563470220112607

Halvorsen, R., \& Pollakowski, H. O. (1981). Choice of functional form for hedonic price equations. Journal of Urban Economics, 10(1), 37-49. https://doi.org/10.1016/0094-1190(81)90021-8

King, A. T. (1976). The demand for housing: a Lancastrian approach. Southern Economic Journal, 43(2), 1077-1087. https://doi.org/10.2307/1057332

Lim, G. C., Follain, J. Jr., \& Renaud, B. (1984). Economics of residential crowding in developing countries. Journal of Urban Economics, 16(2), 173-186.

Lopez, E., \& Aroca, P. (2012). Estimación de la inflación regional de los precios de la viviendaen Chile, El Trimestre Economico LXXIX(3), No. 315, 601-630.

McMillan, M. L. (1979). Estimates of households' preferences for environmental quality and other housing characteristics from a system of demand equations. Scandinavian Journal of Economics, 81(2), 174-187. https://doi.org/10.2307/3439958

MINVU. (2004). Capítulo 3. La Vivienda Social en el periódo de ensayos legislativo, en Chile: Un siglo de políticas en vivienda y barrio.

Paredes, D. (2011). A methodology to compute regional housing price index using matching estimator methods. Annals of Regional Science, 46(1), 139-157. https://doi.org/10.1007/s00168-009-0346-Z

Paredes, D., \& Iturra Rivera, V. (2013). Substitution bias and the construction of a spatial cost of living index. Papers in Regional Science, 92(1), 103-117.

Parsons, G. R. (1986). An almost ideal demand system for housing attributes. Southern Economic Journal, 53(2), 347-363. https://doi.org/10.2307/1059418

Pasha, H. A., \& Butt, M. S. (1996). Demand for housing attributes in developing countries: a study of Pakistan. Urban Studies, 33(7), 1141-1154.

https://doi.org/10.1080/00420989650011555 
Ray, R. (1983). Measuring the costs of children: an alternative approach. Journal of Public Economics, 22(1), 89-102. https://doi.org/10.1016/0047-2727(83)90058-0

Richards, B. (1995). Poverty and housing in Chile: the development of a neo-liberal welfare state. Habitat International, 19(4), 515-527. https://doi.org/10.1016/0197-3975(95)00043-F

Rosen, S. (1974). Hedonic prices and implicit markets: product differentiation in pure competition. Journal of Political Economy, 82(1), 34-55. https://doi.org/10.1086/260169
Rubio, R. (2006). Lecciones de la política de vivienda en Chile. Bitácora Urbano-Territorial, 10, 197-206.

Soto, R., \& Torche, A. (2004). Spatial inequality, migration, and economic growth in Chile. Cuadernos de Economía, 41, 401424.

Wooldridge, J. (2012). Introductory econometrics: a modern approach ( $5^{\text {th }}$ ed.). Mason: South-Western. 